\title{
The Sun Health Research Institute Brain Donation Program: Description and Experience, 1987-2007
}

\author{
Thomas G. Beach · Lucia I. Sue · Douglas G. Walker • Alex E. Roher • \\ LihFen Lue · Linda Vedders · Donald J. Connor · Marwan N. Sabbagh • \\ Joseph Rogers
}

Received: 23 August 2007 / Accepted: 8 November 2007/Published online: 18 March 2008

(C) The Author(s) 2008

\begin{abstract}
The Brain Donation Program at Sun Health Research Institute has been in continual operation since 1987, with over 1000 brains banked. The population studied primarily resides in the retirement communities of northwest metropolitan Phoenix, Arizona. The Institute is affiliated with Sun Health, a nonprofit community-owned and operated health care provider. Subjects are enrolled prospectively to allow standardized clinical assessments during life. Funding comes primarily from competitive grants. The Program has made short postmortem brain retrieval a priority, with a 2.75 -h median postmortem interval for the entire collection. This maximizes the utility of the resource for molecular studies; frozen tissue from approximately $82 \%$ of all cases is suitable for RNA studies. Studies performed in-house have shown that, even with very short postmortem intervals, increasing delays in brain retrieval adversely affect RNA integrity and that cerebrospinal fluid $\mathrm{pH}$ increases with postmortem interval but does not predict tissue viability.
\end{abstract}

T. G. Beach $(\bowtie) \cdot$ L. I. Sue · D. G. Walker .

A. E. Roher - L. Lue - L. Vedders - D. J. Connor .

M. N. Sabbagh · J. Rogers

Sun Health Research Institute, Sun City 85351, USA

e-mail: thomas.beach@sunhealth.org
Keywords Brain banking - Neuropathology ·

Postmortem · Autopsy - Tissue banking ·

RNA $\cdot \mathrm{pH} \cdot$ Cerebrospinal fluid $\cdot$ Postmortem interval

\section{Introduction}

Purpose and mission

The clinical syndromes generated by Alzheimer's disease (AD) and other neurodegenerative disorders are not pathognomonic diagnostic phenomena. Neuropathological examination of the postmortem brain is the only means by which a definite diagnosis can be attained. The purpose of brain banks is to provide neuropathologically characterized brain tissue to basic scientists, enabling them to discover the underlying molecular mechanisms specific to each disease, thereby allowing the design of appropriate therapeutic interventions. A detailed understanding of the genetic and molecular processes of disease pathogenesis, obtained by comparative study of diseased and non-diseased brain tissue, remains the major approach to finding such interventions. It is noteworthy that for both Alzheimer's and Parkinson's diseases, the existing approved pharmacotherapies are all based on neurotransmitter deficiencies identified from study of postmortem brains more than 30 years ago. The subsequent divergence of basic scientific efforts into in vitro work has not generated 
new medicines for these diseases. A return to basic studies of human brain, using new and powerful technologies, is needed to generate a new wave of fundamental discoveries.

The study population and research site

The primary population under study consists of the retirement communities of northwest greater Phoenix, especially Sun City, Sun City West and Sun City Grand. A profile of these communities has been constructed using data from the US Census Bureau (2000) and from the files of the Sun Cities Area Historical Society. All of the communities have as residency requirements a minimum age of 55 years. The populations of Sun City, Sun City West and Sun City Grand, respectively, are 38,306, 26,344 and 9,270 (total of 73,920 as of 2000). Sun City, first established in 1960, was one of the first planned retirement communities in the United States. Sun City West and Sun City Grand followed, in 1978 and 1996, respectively. Due to a lack of new land availability, the populations of all three communities have stopped increasing. The population of Sun City has been maintained at about 40,000 for 3 decades, suggesting that a continued influx of new retirees will maintain the populations of all of the communities. Future new developments are already planned, with Sun City Festival Ranch now in its early stages. This latest community is expected to add another 12,000 residents by 2010 . Additionally, surrounding areas contain a mix of retirees and young families.

Although migration of retirees to the region occurred initially in three major waves, coinciding with the establishment and marketing of housing developments in Sun City, Sun City West and Sun City Grand, the residents are all very similar, being composed overwhelmingly of elderly, well-educated, Caucasian, middle and upper income individuals originating most commonly from Midwestern US states. Initially there must have been some age differences between the communities due to the differences in their construction time, but continued replacement of initial residents with later migrants has almost erased the evidence of this, as the median ages of the residents are 75, 78 and 75, for Sun City, Sun City West and Sun City Grand, respectively. The average residency time in Sun City is 12.6 years. As there is very little outmigration, the turnover is mostly due to deaths. Of the original Sun City population, $90 \%$ were replaced by a second generation of retirees by 1990 .

\section{Sun Health Research Institute}

Sun Health Research Institute (SHRI) is an affiliate of Sun Health Corporation, a non-profit, community owned and operated health care provider. What is now known as Sun Health was first conceived in 1965 and was intended to serve the needs of Sun City, Arizona, one of the first planned retirement communities. Sun Health now serves not only the original Sun City but also the adjacent retirement communities of Sun City West and Sun City Grand as well as northwest greater Phoenix in general, all of which have experienced rapid growth of both retirement and non-retirement populations. Services provided by Sun Health include medical insurance, two acute care hospitals, extended and hospice care, outpatient clinics and Alzheimer care residences. Sun Health has recently announced that it will merge with Banner Health, a larger not-for-profit health care provider with multiple facilities throughout greater Phoenix as well as California, Utah and Colorado.

Sun Health Research Institute was established in 1986 with funds from Sun Health operations revenue and charitable contributions to the Sun Health Foundation. Initially known as the Institute for Biogerontology Research, the Institute has grown into one of the world's largest privately-funded research centers for age-related disorders. The focus of the Institute's scientific work has been, since its inception, Alzheimer's disease, with substantial Parkinson's disease and arthritis research beginning in 1996. More recently there have been extensions into fibromyalgia, orthopedic and prostate cancer research. Since 1998, the Institute has been part of the Arizona Alzheimer's Consortium (AAC), a statefunded alliance that includes Sun Health Research Institute, the University of Arizona, Tucson Veteran's Administration Medical Center, Barrow Neurological Institute, the Arizona Mayo Clinic, Arizona State University and the Banner Health/Good Samaritan Hospital system. The same consortium was awarded a National Institutes on Aging Alzheimer's Disease Core Center (ADCC) in 2001 and a state-funded Arizona Parkinson's Disease Center in 2002. Both of these are headquartered at SHRI. 
The Brain Donation Program at Sun Health Research Institute

The Brain Donation Program has been in existence since 1987 and has enrolled more than 2500 donors over that time, which constitutes about $2 \%$ of the current combined populations of the surrounding retirement communities. Of these, 1042 donors have expired and their brains have been collected and stored, while there are 1061 living donors. Donors have all volunteered specifically for the program and are highly motivated, with an annual drop-out rate of only $1.8 \%$. Recruitment relied initially on hospital staff, who obtained consents from family members of individuals who died while admitted. Recruitment gradually became almost entirely done on a prospective basis, primarily by word-of-mouth, through interactions of the population with physicians and nursing staff belonging to the Sun Health provider network, and through public speaking events and tours of the Institute given by Institute staff to community groups and the general public. Institute staff give approximately 60 such public interactive events each year. Relatively frequent media releases also contribute to recruitment. Eligibility criteria for the Program are simple in that the subjects must be free of hazardous infectious diseases and must consent to annual clinical assessments at SHRI. Additionally, at least two years of the applicant's private medical records must be received and reviewed by Brain Donation Program staff prior to acceptance. The medical records review is directed mainly at excluding hazardous infectious disease conditions. All enrolled subjects or legal representatives sign an Institutional Review Board-approved informed consent form allowing both clinical assessments during life and several options for brain and/or bodily organ donation after death. A separate section requests the subject to allow or disallow DNA isolation and storage as well as genetic testing. Donors are allowed to withdraw from the program at any time. When a donor loses his/her mental capability, ordinarily a family member will be appointed as the donor's legal representative. That legal representative would then have the power to withdraw the donor from the program. The informed consent has a section that fully discloses the possible commercial use of our tissue, stating that SHRI, personnel from SHRI, personnel from other institutions, or other organizations that utilize our tissue may obtain monetary benefit from the use of the tissue.

Between 1987 and 1995 brain donors did not receive formal neuropsychological testing. Their mental status was determined by requisitioning medical records from their primary care physicians, neurologists, psychologists and psychiatrists, and through telephone interviews with family members and caregivers, both at the time of enrollment and in the immediate postmortem period. In 1996 a clinical psychologist was hired and from then onwards, a standardized neuropsychological screening assessment has been administered to most of the subjects enrolled in the Brain Donation Program. Also since 1996, most donors have received a standardized neurological evaluation tailored to detect overt and incipient movement disorders. In 2000, the clinical operations of the Program were greatly expanded, with the hiring of a neurologist, another neuropsychologist and associated support staff, allowing the administration of a full neuropsychological test battery. If a previously undetected medical abnormality is discovered in the course of the annual clinical assessment, the donor is informed and advised to visit their physician for further investigation and/or treatment. The SHRI physician will also ask the donor's permission to inform their private physician of this finding.

\section{Consideration of sampling issues}

Subjects from the Sun Cities are not an accurate representative sample of the entire US elderly population, in that they lack racial diversity and are more highly educated, have higher incomes and live longer than the average US citizen. Although the study population lacks the diversity of the general US population, there are advantages of using a more homogeneous group. The use of homogeneous populations with minimal genetic and environmental variability decreases the subject number required to attain adequate statistical power. This has been recognized by many researchers and has been used, for example, by groups utilizing isolated populations to study inheritance (Adachi et al. 1992; Johanneson et al. 1999; Lio et al. 2003; Mathews et al. 2004; Peschken and Esdaile 1999). However, studying a homogeneous group allows the possibility of missing 
disease characteristics resulting from alleles that may be enriched in some ethnic groups but not in others.

The effect of selection bias on the study population must be considered, as autopsy studies do not represent random sampling. A recent study has shown that subjects selected for autopsy do not differ appreciably from those that are not autopsied (Lim et al. 1999) but this may differ with locale. The issue of "volunteer bias" has been raised, as some studies have suggested that volunteers generally come from a higher socioeconomic background than non-volunteers (Gustavsson et al. 1997; Mandel et al. 2000; Sofuoglu et al. 2000). Volunteer bias may apply differentially to normal and diseased subjects, as normal subjects are almost always true volunteers while diseased subjects are often enrolled by family members after they have lost independent decisionmaking capacity. Very elderly normal control subjects might even be regarded as "supernormals" possessing a general genetic resistance to disease. We have considered this possibility for our study population. Queries of our database have shown, however, that our Alzheimer's disease and non-demented control subjects have generally similar prevalences of major disease conditions (Table 1). Control subjects have a substantially higher prevalence of cancer than AD subjects. Also, as the subjects had essentially the same age at death, the possibility of a "survivor bias" between the two groups is ruled out. The greater prevalence of a medical history of

Table 1 Comparison of AD and control subjects-age at death and disease class prevalence

\begin{tabular}{lll}
\hline Classification & $\begin{array}{l}\text { Alzheimer's } \\
\text { disease }\end{array}$ & $\begin{array}{l}\text { Non-demented } \\
\text { controls }\end{array}$ \\
\hline Age at death & 80.5 & 79.9 \\
Coronary artery & 16 & 7 \\
$\quad$ disease, \% & & \\
Stroke, \% & 7 & 3 \\
Diabetes, \% & 9 & 7 \\
Cancer, \% & 10 & 16 \\
Asthma/COPD, \% & 9 & 7 \\
Macular degeneration, & 3 & 4 \\
$\quad \%$ & & 9 \\
Cataracts, \% & 7 & 13 \\
Osteoporosis, \% & 9 & 4 \\
Hearing impairment, \% & 2 & 17 \\
Hypothyroidism, \% & 12 & \\
\hline
\end{tabular}

coronary atherosclerotic disease and stroke in $\mathrm{AD}$ subjects supports many previous similar reports.

\section{Brain Donation Program Database}

Prior to 1998, records were kept on paper in binders. With the initiation of the computerized database, the essential aspects of these records, including demographic, medical history and neuropathological findings, were abstracted and entered into the computerized database. Since 1998, the Institute has developed a sophisticated database and database management protocols, largely engineered by a contracted professional industrial database consultant. The clinical and neuropathology components of the Brain Donation Program Database were designed together and are completely integrated. The Database is a customized elaboration of Microsoft Access and My Sequel off-the-shelf programs. The current combined clinical and neuropathology components take up 218 megabytes. The Database is composed of 51 matrices with 1905 fields (separate data categories) which collectively contain data pertaining to basic demographic information, medical history, results of standardized clinical assessments and, for autopsied subjects, neuropathologic data, tissue inventory and records of tissue requests and shipments. The Database contains 53 forms to facilitate data entry and 75 different standing data reports that can be generated with a single keystroke. The Database is also used to ensure that scheduling of clinical assessments is done at appropriate intervals. The current neuropathology subsection of the Database has 330 fields, of which the National Alzheimer's Coordinating Center (NACC) Neuropathology Data Set is a subset. Numerous additional fields beyond the latter include in-house grading methods for plaques, tangles, Lewy bodies and white matter rarefaction, as well as fixed tissue quality, RNA quality and current inventory of 160 fields for fixed tissue, frozen tissue, CSF and blood serum. The Neuropathology Database tracks tissue requests and requestors.

The Database is backed up automatically every day on two servers administered by Sun Health Information Services, located at two sites about 5 miles apart. Storage of data in both locations ensures that structural damage to one server (e.g. fire) does not result in irretrievable loss. Both servers store daily copies of databases for the preceding 30 days; 
older copies are sent to a commercial server contracted for this purpose. Storage of older database copies allows the recovery of an intact database in the event of inadvertent errors in database operation, hardware malfunction or software malfunction.

The SHRI Brain Donation Program Database has been managed by informal groups that have included the database designer, a statistician, the directors of the clinical and neuropathology cores and the major database operators. This arrangement has worked very well as it includes the individuals who use the database day-to-day, the physician-scientists that will be collecting the data, and the database designer, who can make changes to the database as necessary.

Confidentiality of human subject data in the Database is assured by multiple safeguards which restrict access to personal identifying information such as name, date of birth, date of death, address and gender. Data entry is restricted to as few personnel as possible. Access to the Database requires a unique user name and password, and all transactions are tracked and stored in an electronic log, allowing identification of inappropriate or incorrect usage by any individual. Access to the Sun Health local area network is protected by a firewall maintained by Sun Health Information Services. Paper copies of subject records are kept in locked filing cabinets in the offices of the major database operators. Sun Health Research Institute has been issued a Certificate of Confidentiality by the US Secretary of Health and Human Services, protecting human subjects' data from court subpoena.

Institute researchers are able to obtain an up-todate copy of the Database, minus personal identifying information, at any time upon request. A standing query is used to produce this, following which the database copy is copied onto a portable memory storage device which the researcher may then load onto his/her own computer. Standard Microsoft Access software, which is provided by Sun Health, will run the database copy. For database queries involving detailed knowledge of clinical or neuropathologic criteria, the directors of neurology and neuropathology assist the researchers with query design.

All data are subjected automatically to an error checking program that identifies out of range, illogical and missing data. In addition, a random sample of subject records is compared directly with data forms (paper copy) on a periodic basis to reduce data entry mistakes.

Flow of subjects through the Brain and Body Donation Program Clinical Core

The flow of subjects through the Brain and Body Donation Program Clinical Core over the 5 year period between January 1, 2001 and December 31, 2006 is illustrated in Fig. 1. Note that this summary applies exclusively to subjects seen at Sun Health Research Institute and does not include subjects that were seen clinically at other institutions participating in our Arizona ADCC. On January 1, 2001 there were 255 living subjects enrolled in the Brain and Body Donation Program. This initial input of subjects was supplemented by 1078 new subjects recruited by the Clinical Core over the following 5-years, giving a total of 1332 subjects that flowed through the Clinical Core over this time period. There are two major pathways that subjects followed over this 5-year period, depending on whether or not they received a standardized clinical assessment by Core personnel. Although it is a requirement of the Program that donors consent to annual standardized clinical assessments at SHRI, and considerable efforts are expended to have every subject assessed, inevitably some (currently less than 10\%) of our living subjects die without a standardized assessment. There are various reasons why not all subjects are assessed. Some subjects are in a terminal phase of illness when they register with the Program and die or become incapacitated before an assessment can be done, while others have difficulty scheduling an appointment for various reasons. A common impediment is a lack of someone to bring them in if they are not able to drive themselves. Some donors had enrolled in the Program prior to when clinical assessments became mandatory and are therefore allowed to remain as brain donors only. For normal control cases that die without a standardized clinical assessment at SHRI, or whose last SHRI assessment was more than a year prior to death, an effort is made to obtain postmortem functional assessments by using telephone interviews with informants. The Dementia Questionnaire (DQ) has been used for this purpose, with 42 postmortem DQ assessments obtained between July 1, 2000 and August 1, 2007. The DQ has been validated in subjects who had both a premortem clinical diagnosis 
Fig. 1 Subject flow through the Brain Donation Program 01/01/01-12/31/ 06. Percentages are calculated with respect to total subject input

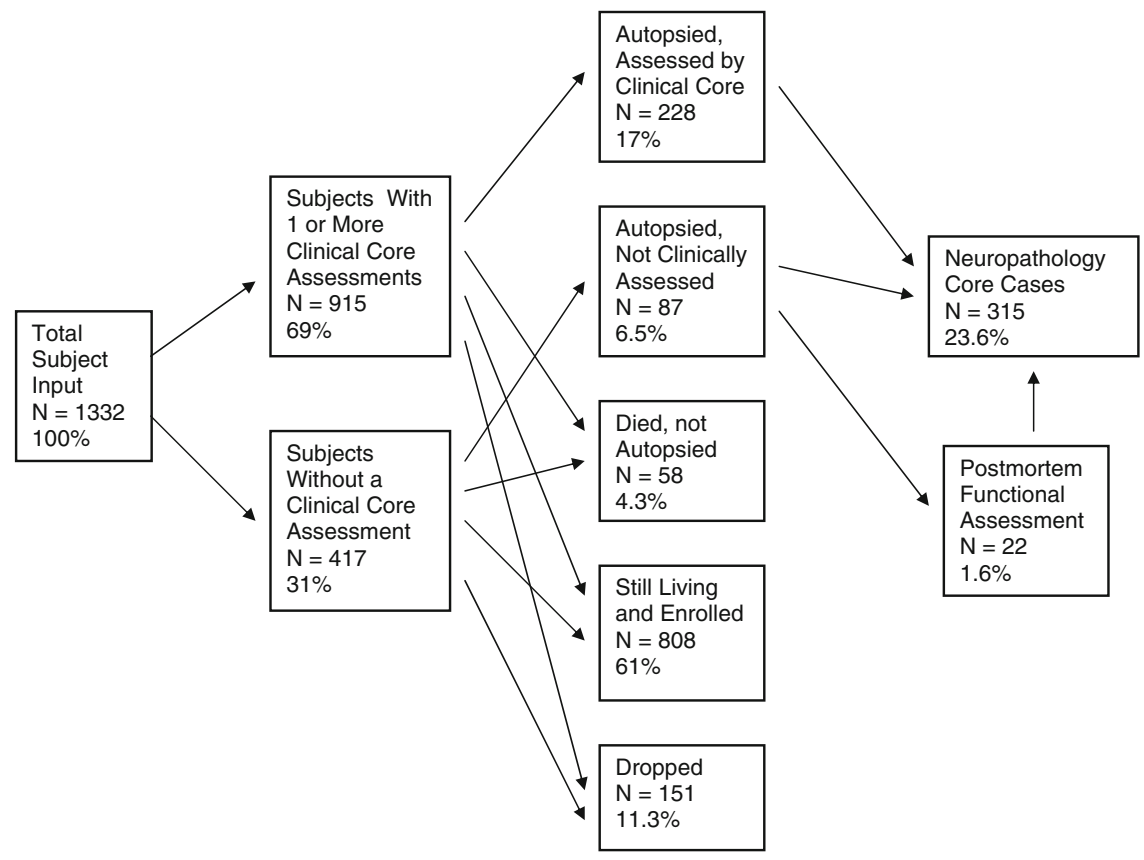

and a postmortem DQ (Ellis et al. 1998). The DQ has a high specificity and sensitivity for the presence of dementia (93\% and $89 \%$, respectively), and also has a high interrater agreement (98\%).

Neuropathology Core and Brain Banking Operations

\section{Dedication to short postmortem interval}

Since the inception of the Brain Donation Program, the overriding organizing principle has been that the brain must be removed and processed as rapidly as possible. The median postmortem interval (PMI), defined as the time elapsing between death and brain removal, for all 1042 of our necropsied subjects, is $2.75 \mathrm{~h}$ (mean 3.92; standard deviation 5.11; range 1-70). There is a moderately extensive literature on the relationship between PMI and brain tissue quality, which will not be exhaustively summarized here, but it is apparent that deterioration of molecular entities after death varies widely depending on what is being measured. Highly volatile energy storage molecules such as ATP disappear within minutes (Ravid et al. 1992), catecholamines drop precipitously within the first few hours (Hynd et al. 2003; Palmer et al. 1988; Spokes and Koch 1978; Spokes 1979) while highmolecular-weight DNA may be stable for up to
20 days after death (Ludes et al. 1993). Some enzyme activities actually increase after death, for example, creatine kinase activity is increased more than ten-fold at $2 \mathrm{~h}$ postmortem (Karkela 1993). Most protein and RNA species are surprisingly stable up to 40-50 h postmortem (Cummings et al. 2001; Ferrer et al. 2007; Hynd et al. 2003; Johnson et al. 1986; McGeer and McGeer 1976; Preece and Cairns 2003; Stan et al. 2006; Tomita et al. 2004; Vonsattel et al. 1995). As the majority of biomedical research is done on proteins and RNA, this might suggest that postmortem intervals up to 36 or even $48 \mathrm{~h}$ might be sufficient for authoritative studies, but there is also evidence that appreciable numbers of specific proteins and RNA transcripts show large PMI-dependent reductions, even within the first 4-8 h (Catts et al. 2005; Ferrer et al. 2007; Hynd et al. 2003; Pardue et al. 1994). Variability in postmortem preservation of different mRNA transcripts may be due to differing tertiary structures or normal physiological half-lives, which range from minutes to days. For example, c-fos mRNA has a half-life of 15 min while that for globin mRNA is $50 \mathrm{~h}$ (Hynd et al. 2003). Some intensely-studied proteins are markedly degraded within the first $4-8 \mathrm{~h}$ of death, including $\alpha$-synuclein and sarkosyl-insoluble tau (Ferrer et al. 2007a). The postmortem integrity of post-translational protein modifications is largely unknown, 
although it has been reported that tau protein is dephosphorylated within 30 min after death (Gartner et al. 1998).

We have evaluated RNA integrity in 157 cases (mean PMI $3.1 \mathrm{~h}$ ) from our brain bank using qualitative RNA agarose gel electrophoresis. The presence of two clearly distinct and dominant bands, corresponding to the ribosomal $28 \mathrm{~S}$ and $18 \mathrm{~S}$ RNA species, as recorded by a single observer blinded to all case data, was used to define acceptable RNA. Loss or smearing of these bands was used to indicate degradation levels making the sample unsuitable for study. Using these criteria, $133 / 157$, or $82 \%$ of our samples were suitable for RNA studies and were used successfully. Comparison of PMI's from cases giving suitable and unsuitable RNA showed a significantly shorter mean PMI in the suitable samples (2.75 vs $3.5 \mathrm{~h}$, two-tailed unpaired $t$-test; $P=0.04$ ). These results suggest that even small differences in PMI within a rapid autopsy program can have a significant effect on RNA integrity. As a further comparison, programs with average PMI's of $16 \mathrm{~h}$ or more have reported one-third to one-half of cases have RNA suitable for molecular research methods (Vanderburg et al. 2005; Vonsattel et al. 1995) whereas we have found $82 \%$ of cases suitable. These results and the brief literature review presented here indicate that a short PMI clearly allows optimal use of the resource but that all postmortem studies must evaluate the influence of PMI as it is dependent on the specific molecular forms under investigation.

\section{On-call brain removal teams}

The maintenance of a rapid autopsy program requires sufficient staffing to prevent "burnout". Most rapid autopsy programs fail because of understaffing. Our experience has led to the conclusion that it is advisable to limit on-call periods for any one individual to no more than 4 months per year. The minimum number of persons required for each callout is two, for both safety and efficiency reasons. We have three rotating on-call teams, each consisting of a team leader and one assistant. The team leaders, who are employees of the Neuropathology Core of the Brain Donation Program (they also serve as histology technicians during regular hours), receive training from the neuropathologist and coordinator and are on call every third month, while the assistants, derived from volunteers amongst the entire SHRI scientific, technical and administrative staff, generally serve for 1-3 months per year. Team leaders and assistants are paid a bonus for each callout. As another strategy to avoid on-call team burnout, we continually optimize procedures to minimize brain processing time. Generally we complete all procedures in less than $2.5 \mathrm{~h}$ and the total time a team member spends on a call, including transportation to and from their home, is between 3 and $4 \mathrm{~h}$. To expedite brain processing, we always have made preparations for 2-3 autopsies into the future. Having a permanent dedicated autopsy suite enables all tools and equipment to be laid out ready for use; we also prelabel all containers and bags.

\section{Time-of-death telephone protocol and cadaver transport}

When subjects registered into the Brain Donation Program die, their caregivers, usually at a nursing home, follow the instructions given to them by the family, which were mailed to the family at the time of acceptance into the Program. The instructions are simple and require only that the caregiver telephone the Institute as soon as possible after death. If the call is after-hours, it is transferred to the operator at one of Sun Health's acute care hospitals. The on-call team leader is then paged by the hospital operator and calls in to receive the contact information. The team leader then calls the contact, usually the caregiver at the nursing home, and conducts a short interview to ascertain the subject's identity, confirm that they are registered in the Program, and record the subject's current charted medical history conditions. The team leader also asks whether the subject has specific hazardous infectious diseases (see later section on safety for details). Subjects who die within the greater Phoenix metropolitan area are transported to the SHRI morgue by a contracted commercial cadaver transport company. Longer distances have proportionately greater charges and the PMI becomes progressively longer. For these reasons, we only accept cases that die within an approximate 50 mile radius and the informed consent details this so that the family is aware. These transportation companies normally serve funeral homes on a $24 \mathrm{~h}$ basis and therefore are ideally suited for our rapid autopsy program. All charges are borne by the Program; 
donors and their families are not charged for any aspect relating to their donation.

\section{Blood and CSF draw, brain removal, gross dissection and initial tissue processing}

Prior to removing the brain, cerebrospinal fluid (CSF) is drawn from the lateral ventricles and heart blood is drawn from the left ventricle by transthoracic puncture, using $30 \mathrm{ml}$ disposable syringes fitted with $8 \mathrm{~cm}$ long, 18 guage needles. The CSF is ejected into $15 \mathrm{ml}$ disposable Falcon tubes for centrifugation while the blood is converted to serum by introduction into standard serum separator vacuum tubes $(7 \mathrm{ml})$ prior to centrifugation. Although a small fraction of blood is also taken into EDTA vacuum tubes ( $4 \mathrm{ml}$ each) for preparation of plasma, this is not directly comparable to plasma from living subjects as extensive postmortem coagulation would have removed many clotting factors and other proteins. About $20-30 \mathrm{ml}$ of CSF, 5-10 $\mathrm{ml}$ of serum and $4 \mathrm{ml}$ of plasma are generally obtained. A 2-3 ml sample of blood serum is sent to a commercial clinical pathology laboratory for syphilis, HIV and hepatitis A, B and C serology. Remaining blood serum as well as CSF is centrifuged and supernatants from both blood serum and CSF are aliquotted into $1 \mathrm{ml}$ microcentrifuge tubes and stored frozen at $-80^{\circ} \mathrm{C}$. Postmortem CSF has been said to be unsuitable for research purposes due to postmortem changes or due to its ventricular origin, but these opinions appear to be purely anecdotal as we have conducted an extensive literature search and found no published evidence supporting these claims. We have conducted extensive studies on postmortem CSF (Castano et al. 2006) using Western blot, ELISA and proteomic methodology and have obtained results similar to those published by many other groups, who have all used CSF from living subjects. In our opinion, the benefits obtained by having precise neuropathological diagnoses for subjects greatly outweighs the disadvantages conferred by the presence of any minor postmortem changes. We are presently conducting a detailed proteomic comparison of CSF from living and deceased subjects. Similar considerations apply to the usage of postmortem blood fractions, which we have also investigated extensively (Kuo et al. 1998, 1999, 2000a; Rogers et al. 2006).
Also prior to brain removal, and prior to CSF draw, samples are taken of temporalis muscle and scalp. Many neurological diseases can be diagnosed or studied in muscle or skin and therefore we fix and/ or freeze these samples along with the brain tissue. We have published results for $\mathrm{A} \beta$ concentrations in these temporalis muscle samples (Kuo et al. 2000b) and have done unpublished work on scalp samples from $\mathrm{AD}$ and control subjects (finding no immunohistochemically-detectable $\mathrm{A} \beta$ ).

Brain removal is accomplished in the standard fashion with an oscillating electric saw. To minimize bacterial contamination of brain tissue, the scalp is washed with an antibacterial solution. After the skull cap is removed, the brain team leader changes to new sterile gloves before moving the brain to the cutting board, which has been prepared by wiping down with $70 \%$ ethanol. These precautions are in the interests of our postmortem cell culture teams, which regularly culture glial and vascular cells from the postmortem brain tissue (Lue et al. 1996; Lue and Walker 2002; Rogers et al. 2002; Walker and Lue 2005). The brain is removed with as much cervical spinal cord as possible. Following brain removal, the pituitary gland is dissected from the sella turcica. Gross neuropathologic examinations on brain external surfaces, coronal cerebral slices and parasagittal cerebellar slices are performed by the neuropathologist during working hours. After-hours brains are photographed at the time of removal, whole and after slicing with a digital camera (Nikon D50) and dedicated software that transmits the images directly to a computer harddrive (Nikon Capture 4). By reviewing the digital images, the neuropathologist is then able to perform a gross description on brains removed and processed after-hours. The images may also be used for morphometric analysis without the usual complication of correcting for volume changes due to fixation.

The details of the brain dissection are as follows. The olfactory bulbs and tracts as well as the pineal gland are removed and the cerebellum and brainstem are severed from the cerebrum by a transverse cut across the rostral pons. The leptomeninges are stripped from both cerebrum and cerebellum/brainstem for storage as research material (Roher et al. 2003). The cerebellum is separated from the brainstem by severing the cerebellar peduncles. Each hemicerebellum is sliced into 4-5 segments in the parasagittal plane. The brainstem is sliced into left 
and right halves. The cerebrum is sliced into approximately $0.8-1 \mathrm{~cm}$ segments in the coronal plane. The left side slices are used for immersion fixation in freshly-prepared phosphate-buffered $4 \%$ paraformaldehyde while the right side slices are rapidly frozen between sheets of dry ice $(20 \times$ $20 \times 3 \mathrm{~cm})$.

This method of brain processing differs from the conventional neuropathological examination, in which the whole or half of the brain is immersed in formaldehyde for 7-14 days before slicing. Although it has been argued that fresh-slicing detracts from the neuropathologic gross exam, we feel that it is essential to slice the brain fresh, both to enable rapid freezing and optimum fixation. Freezing an intact hemisphere slowly on dry ice or by placing it in an ultralow-temperature freezer results in severe icecrystal artifact (Vonsattel et al. 1995), rendering the tissue unsuitable for cryostat-section histological examination, which has become increasingly important as a method for molecular studies, especially those utilizing confocal laser-capture microscopic analysis. Also, the long-entrenched idea that rapid freezing in liquid nitrogen or similar fluids is essential for molecular biological studies is simplistic and incorrect. In fact, rapid freezing may cause membrane damage while slow freezing in isoosmotic cyroprotectant is optimal for synaptosomal preparations (Hynd et al. 2003). Our experience has shown that freezing rapidly between sheets of dry ice gives morphologically intact tissue suitable for a wide range of molecular biological procedures, including Western blot, ELISA, Northern blot, insitu hybridization, gene microarray, proteomics and RT-PCR.

Similarly, fixing the brain whole or as an intact hemisphere is not an optimal use of the resource as this results in extreme fixation gradients across the tissue, with brain surfaces becoming over-fixed while interior regions are under-fixed. These fixation gradients make even semi-quantitative immunohistohchemical evaluation very difficult, although a minority of epitopes are tolerant to this. While perfusion-fixation of the postmortem brain through the circle of Willis (the entire cerebrum or one hemisphere can be fixed this way) is the optimal fixation method, this is timeconsuming and we have found that fixation of $1 \mathrm{~cm}$ thick slices for $24-48 \mathrm{~h}$ at $4^{\circ} \mathrm{C}$ is a reasonable compromise (Beach et al. 1987).
To aid in the production of uniformly-thick fresh brain slices for freezing and fixation, we have developed a brain slicing apparatus (jig) that holds the brain together while being sliced. With the assistance of a retired engineer living in Sun City and a contracted fabrication company (AvTek, Inc, Phoenix, AZ), we have enabled its semi-automated duplication by entering the 3-dimensional plans for the apparatus onto a computer. We have made this available and known to other brain banks.

Fixation is continued for 2 days at $4^{\circ} \mathrm{C}$. Following fixation, diagnostic tissue blocks are taken from 28 brain regions (Table 2) for embedding in paraffin wax; additionally, 8 large (about $3 \times 4 \mathrm{~cm}$ ) tissue blocks, representing all cerebral lobes as well as cerebellum and brainstem (Table 2), following cryoprotection in $2 \% \mathrm{DMSO} / 20 \%$ glycerol, are sectioned at $40 \mu \mathrm{m}$ on a sledge-type freezing microtome. These thick sections are superior to standard autopsy brain paraffin blocks for both silver stains and immunohistochemistry, due to their relatively light fixation (Beach et al. 1987; Leong and Gilham 1989), thickness (allowing full visualization of 3-D structure), structural integrity (allowing processing as free-floating sections, which improves antibody access and washing) and lack of exposure to hot paraffin wax (Pollard et al. 1987). These large-format sections also offer the opportunity for grading of periventricular white matter rarefaction (Fig. 2a) and an extensive survey for microscopic infarctions. Pre-cut free-floating $40 \mu \mathrm{m}$ sections, as well as unsectioned fixed wet brain blocks, are stored at $-20^{\circ} \mathrm{C}$ in a solution composed of $30 \%$ ethylene glycol, $30 \%$ glycerol in $0.1 \mathrm{M}$ phosphate buffer. Sections prepared in this manner have been used successfully for immunohistochemical studies after two decades of storage.

\section{Diagnostic stains}

Sections from paraffin blocks are cut at $6 \mu \mathrm{m}$ and stained with hematoxylin and eosin (H \& E). Paraffin sections from the anterior cingulate gyrus, amygdala, entorhinal cortex, middle frontal gyrus, middle temporal gyrus, inferior parietal lobule, anterior medulla and olfactory bulb are stained immunohistochemically for $\alpha$-synuclein to identify Lewy bodies and Lewy-related neurites. Sections from the large frozen blocks are stained with Campbell-Switzer, Gallyas (Braak and Braak 1991) and Thioflavine S methods 
Table 2 Brain regions sampled for diagnostic histopathology and inventory

\begin{tabular}{|c|c|c|}
\hline Brain region & $\begin{array}{l}\text { Paraffin } 6 \mu \mathrm{m} \\
\text { sections }\end{array}$ & $\begin{array}{l}\text { Frozen } 40 \mu \mathrm{m} \\
\text { sections }\end{array}$ \\
\hline Superior frontal gyrus & No & Yes \\
\hline Middle frontal gyrus & Yes & Yes \\
\hline Precentral gyrus & Yes & No \\
\hline Postcentral gyrus & Yes & No \\
\hline Superior parietal lobule & No & Yes \\
\hline Inferior parietal lobule & Yes & No \\
\hline Anterior cingulate gyrus & Yes & Yes \\
\hline Superior temporal gyrus & No & Yes \\
\hline Middle temporal gyrus & Yes & Yes \\
\hline Inferior temporal gyrus & No & Yes \\
\hline Fusiform gyrus & Yes & Yes \\
\hline $\begin{array}{l}\text { Parahippocampal gyrus at } \\
\text { amygdala }\end{array}$ & Yes & Yes \\
\hline $\begin{array}{l}\text { Parahippocampal gyrus at } \\
\text { head hip. }\end{array}$ & No & Yes \\
\hline $\begin{array}{l}\text { Parahippocampal gyrus at } \\
\text { lat. genic. }\end{array}$ & Yes & Yes \\
\hline Hippocampus at head & No & Yes \\
\hline Hippocampus at body & Yes & Yes \\
\hline Occipital cortex: primary & Yes & Yes \\
\hline $\begin{array}{l}\text { Occipital cortex: } \\
\text { association }\end{array}$ & Yes & Yes \\
\hline $\begin{array}{l}\text { Cerebral white matter: all } \\
\text { lobes }\end{array}$ & No & Yes \\
\hline Caudate nucleus: head & No & Yes \\
\hline Caudate nucleus: body & Yes & Yes \\
\hline Putamen: head & No & Yes \\
\hline Globus pallidus & Yes & Yes \\
\hline Substantia innominata & Yes & Yes \\
\hline Thalamus: anterior & Yes & Yes \\
\hline Thalamus: midpoint & Yes & Yes \\
\hline Hypothalamus & Yes & Yes \\
\hline Mammillary body & Yes & No \\
\hline Subthalamic nucleus & Yes & Yes \\
\hline Substantia nigra & No & Yes \\
\hline Midbrain tegmentum & No & Yes \\
\hline Pons: anterior & Yes & No \\
\hline Pons: midpoint & Yes & Yes \\
\hline Cerebellum: vermis & Yes & No \\
\hline $\begin{array}{l}\text { Cerebellum: dentate } \\
\text { nucleus }\end{array}$ & Yes & Yes \\
\hline $\begin{array}{l}\text { Cerebellum: hemispheric } \\
\text { cortex }\end{array}$ & Yes & Yes \\
\hline Medulla: anterior & Yes & No \\
\hline Medulla: posterior & Yes & No \\
\hline
\end{tabular}

Table 2 continued

\begin{tabular}{lll}
\hline Brain region & $\begin{array}{l}\text { Paraffin } 6 \mu \mathrm{m} \\
\text { sections }\end{array}$ & $\begin{array}{l}\text { Frozen } 40 \mu \mathrm{m} \\
\text { sections }\end{array}$ \\
\hline Olfactory bulb and tract & Yes & No \\
Spinal cord: cervical & Yes & No \\
\hline
\end{tabular}

for plaques, tangles and other inclusions while additional sections are stained with $\mathrm{H} \& \mathrm{E}$ to detect and grade periventricular cerebral white matter rarefaction (leukoaraiosis) and microinfarctions (Fig. 2). At a section thickness of $40 \mu \mathrm{m}$, we have found that $\mathrm{H} \& \mathrm{E}$ is superior to Luxol Fast Blue for detection of white matter changes. Additional immunohistochemical procedures are used as needed, including those for phosphorylated tau protein to detect atypical tauopathies, ubiquitin to detect intraneuronal inclusions of frontotemporolobar dementia with ubuiquinated inclusions, and $\alpha \mathrm{B}$-crystallin and/ or phosphorylated neurofilament to detect swollen neurons in corticobasal degeneration. For all stains except $\mathrm{H} \& \mathrm{E}$, positive control sections are always included in order to standardize staining results from batch to batch.

\section{Diagnosis of neurodegenerative disorders}

Diagnostic criteria have been amply discussed in the literature and will not be reviewed here. For a summary of the current general approach, the reader is referred to a recently-published algorithm (Dickson 2005). Published clinicopathologic consensus criteria are used for most conditions, incorporating clinical determinations of cognitive status and the presence or absence of other neurologic signs as well as pertinent medical history. The diagnoses of cases coming to autopsy in the Brain Donation Program since 1997 are given in Table 3. The frequency of different conditions reflects recruiting priorities, which have been focused on normal elderly controls, Alzheimer's disease and Parkinson's disease. Noteworthy, however, are the relatively high frequencies of nonAlzheimer's dementias, particularly dementia with Lewy bodies, progressive supranuclear palsy and hippocampal sclerosis, all of which have often come to autopsy as clinically-diagnosed Alzheimer's disease. Also notable is the frequent co-existence of more than one major neuropathological condition in the same subject. 
Fig. 2 Photomicrographs of $40 \mu \mathrm{m}$ frozen sections stained according to our standard protocols. (a) Frontal lobe stained with $\mathrm{H}$ \& E, showing periventricular white matter rarefaction; (b)

hippocampus stained with the Campbell-Switzer silver method, showing senile plaques and neurofibrillary tangles; (c) neurofibrillary tangles stained with the Gallyas silver method; (d) neuron in the dentate gyrus granular cell layer stained immunohistochemically for phosphorylated tau protein with the AT8 antibody; (e) tufted astrocyte stained with the Gallyas method; (f) thorned astrocyte stained with the Gallyas method; (g) oligodendroglial coiled body stained with the Gallyas method

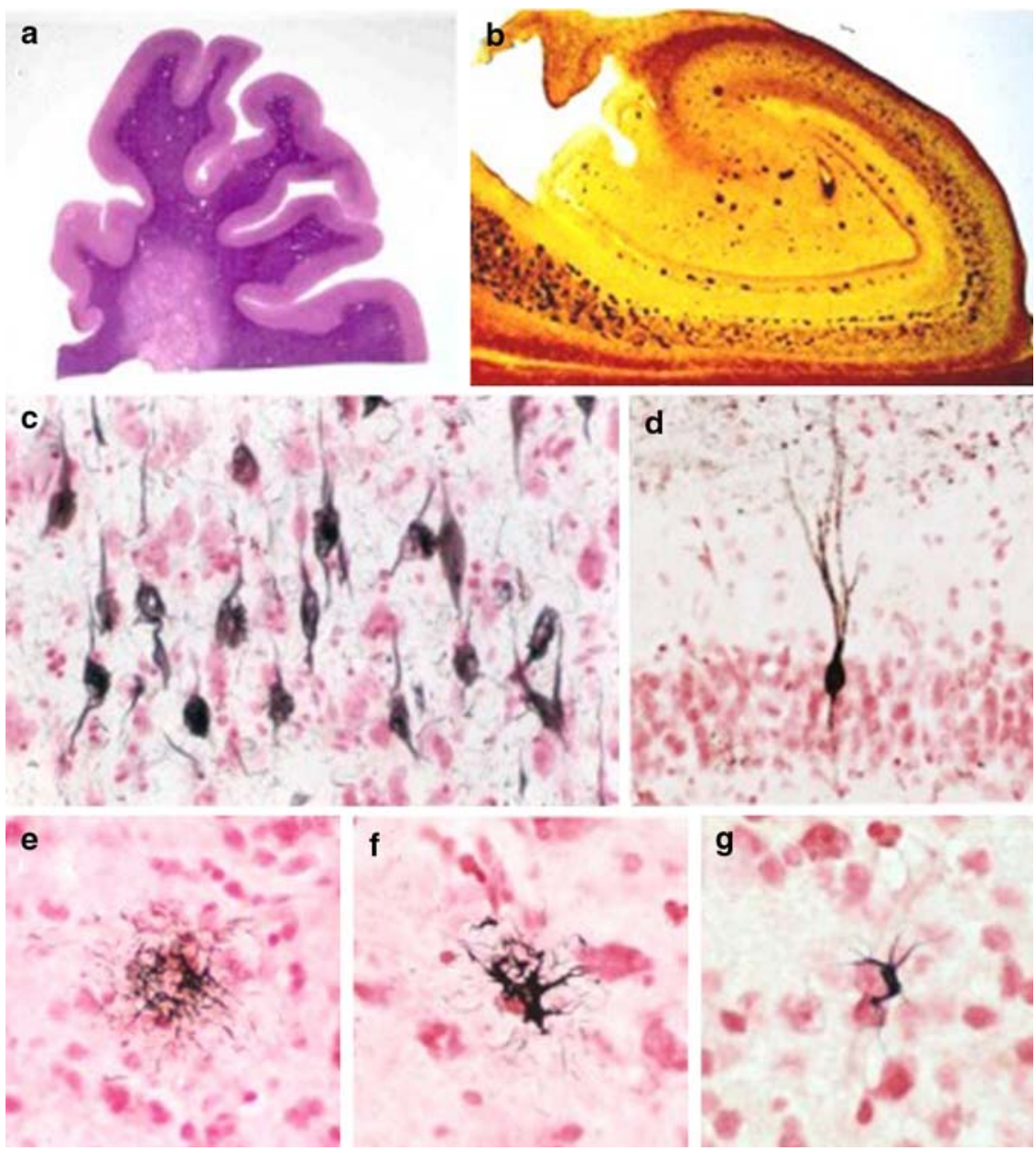

\section{Genotyping and DNA banking}

Since the discovery of the increased risk for Alzheimer's disease that is attributable to the presence of the $\varepsilon 4$ allele of the apolipoprotein $E$ gene (apoE), numerous investigations have shown that some clinicopathologic characteristics of the disease are different in $\varepsilon 4$ carriers vs non-carriers. Therefore it is important, when designing studies involving Alzheimer's disease tissue, to analyze the data taking $\varepsilon 4$ genotype into account. Since January 1999 it has been our objective to genotype every case coming to autopsy, with 730 cases done to date. The testing has been performed using a standard technique (Hixson and Vernier 1990), with DNA isolated from our lightly-fixed cerebellar samples as described previously (Beach et al. 2003). We have found this method more convenient than using fresh-frozen tissue although the method is unsuitable for brain tissue fixed in formalin for the standard interval of 10 days to 2 weeks; in these cases we use fresh-frozen cerebellum. We periodically perform quality control studies, having a series of our apoE-genotyped cases repeated by another laboratory. Isolated DNA remaining after apoE genotyping is stored for future studies. Screening for other mutations associated with neurodegenerative conditions (e.g. triplet repeat expansion diseases, spinocerebellar degenerations, progranulin mutations) is performed by outside collaborating laboratories when family history, clinical features and/or histopathology are suggestive of a particular condition.

\section{Assessment of agonal state}

Agonal status impacts tissue quality, as fever, ischemia-hypoxia and acidosis are deleterious to many 
Table 3 Neuropathological diagnoses, 1997-2007

\begin{tabular}{lrc}
\hline Neuropathological diagnosis & $N$ & $\%$ \\
\hline Normal $^{\mathrm{a}}$ & 119 & 21 \\
Alzheimer's disease $^{\prime}$ & 316 & 56 \\
Dementia with Lewy bodies & 99 & 18 \\
Parkinson's disease & 78 & 14 \\
Vascular dementia & 43 & 8 \\
Progressive supranuclear palsy & 41 & 7 \\
Hippocampal sclerosis & 35 & 6 \\
Dementia lacking distinctive histology & 9 & 2 \\
Multiple system atrophy & 5 & 0.9 \\
Motor neuron disease with dementia & 3 & 0.5 \\
Corticobasal degeneration & 2 & 0.4 \\
Pick's disease & 2 & 0.4 \\
Huntington's disease & 2 & 0.4 \\
\hline
\end{tabular}

As more than one condition was often present in a single subject, the sum of the percentages exceeds 100

a No major clinical neurological diagnosis \& age-consistent neuropathology only

molecules of interest (Harrison et al. 1995; Hynd et al. 2003; Johnston et al. 1997; Li et al. 2004; Morrison-Bogorad et al. 1995; Perry et al. 1982; Spokes 1979). However, agonal status is difficult to determine in elderly subjects, who usually die in a nursing home without close medical supervision. The $\mathrm{pH}$ of $\mathrm{CSF}$ and/or brain tissue has been used as a surrogate marker for agonal status (Ravid et al. 1992). Some studies have reported that when the agonal state, as inferred from clinical data, is expected to have been detrimental, for example in cases of prolonged mechanical ventilation, the $\mathrm{pH}$ is low (e.g. pH 5.5-6.0), while in cases of sudden death it is higher, closer to normal (e.g. 7.0-7.4) (Hardy et al. 1985; Perry et al. 1982). Some enzyme activities and measures of RNA integrity have correlated with postmortem $\mathrm{pH}$, but not in all studies or for all subtypes of these molecules (Kingsbury et al. 1995; Li et al. 2004; Spokes 1979; Stan et al. 2006; Yates et al. 1990). Two recent comprehensive studies may have resolved the variability in prior reports, as it was found that only $\mathrm{pH}$ values under about $6.5-6.8$ were associated with decreased RNA integrity (Li et al. 2004; Stan et al. 2006).

We conducted our own study of postmortem CSF $\mathrm{pH}$ as a marker of tissue viability by correlation with viable cell yield in postmortem glial cultures, reasoning that physiologically damaging agonal conditions would result in a decreased yield of viable cells taken from that tissue.

The viable cell yield from 46 consecutive cell culture cases was compared with their respective CSF $\mathrm{pH}$ and PMI. Brain tissue for culture was obtained from the cerebral white matter of the centrum ovale. Viable cell yield ranged from 0.74 to $6.47 \times 10^{6}$ cells/g brain tissue. The $\mathrm{CSF} \mathrm{pH}$ ranged from 6.36 to 7.19 (mean 6.73). Post-mortem interval ranged from 1.5 to $4.5 \mathrm{~h}$. Multiple linear regression analysis indicated that $\mathrm{CSF} \mathrm{pH}$ was not a significant independent predictor of viable cell yield $(R=0.12$, $P=0.45)$. Postmortem interval, however, was significantly related (inversely) to viable cell yield, ( $R=0.28, P=0.06)$. A surprising result was that PMI was significantly correlated (inversely) with CSF $\mathrm{pH}(R=0.37, P=0.01)$, in agreement with one other group (Catts et al. 2005) but in disagreement with several other reports (Karkela 1993; Kingsbury et al. 1995; Stan et al. 2006). The difference between our results and those of other groups may be due to our uniformly short PMI, as other studies have included many cases with much longer PMIs. It is likely that brain cells surviving after death are generating lactic acid via anaerobic metabolism. As the PMI increases, fewer and fewer cells are alive and eventually all cells will be dead. At some point in this process, it is probable that $\mathrm{pH}$ would eventually stabilize. Therefore studies that have primarily involved cases with longer PMI's may not find any relationship between PMI and $\mathrm{pH}$. We have not performed both RNA integrity assessments and CSF $\mathrm{pH}$ measurement on enough cases to allow a meaningful correlation of these factors as yet.

Our results suggest, therefore, that CSF progressively acidifies with increasing postmortem interval but that it is not a useful predictor of tissue viability, at least for cases with PMIs in the 1-5 h range. We have decided that direct assessment of tissue preservation is preferable to indirect markers such as CSF pH or agonal medical history collection. As RNA is one of the most important molecular species for research uses, we have been using RNA quality, assessed qualitatively in RNA gels as described above, as a general indicator of tissue quality. 
Cryostat sections for biochemical study of small, important brain regions

One of the limitations of brain banking for neurodegenerative disease research is that some of the most important brain regions are very small and just one or two studies may entirely deplete the tisssue. Examples of these small yet vital regions are the entorhinal cortex, hippocampus, amygdala and substantia nigra. To overcome this limitation and distribute tissue from these regions to greater numbers of researchers, we have been sectioning these brain areas on a cryostat and providing researchers with samples of 5-10 cryostat sections per case. This has been found sufficient to allow 5-6 Western blot analyses for proteins of interest and numerous RNA analyses for studies of gene expression. Conservatively, we estimate that this will increase utilization by 10 -fold or greater.

\section{Serial sectioning of substantia nigra for unbiased stereologic morphometry}

Accurate counting of neurons within defined brain regions requires the methods of unbiased stereology (Gundersen et al. 1988; West 1999) and a complete sampling of the brain region of interest. For cases with clinical parkinsonism, as well as many control cases, we have serially sectioned the substantia nigra to allow unbiased estimates of neuron numbers. The entire left side of the substantia nigra is serially sectioned at $40 \mu \mathrm{m}$ on a sliding freezing microtome, with all sections collected and stored appropriately. To date, 146 cases have been serially sectioned in this manner. The method is very time-consuming, however, and as an alternative, researchers should consider biochemical analysis of dopaminergic markers in the striatum as perhaps a more quantitative and sensitive indicator of the integrity of the nigrostriatal dopaminergic system (Beach et al. 2004).

\section{Brain and Body Donation Program with full autopsies}

The SHRI Brain Donation Program expanded its operations in September 2005 by offering wholebody donation to all enrolled subjects and to newlyrecruited subjects. Since that time, approximately 600 former brain-only donors have consented to whole- body donation and we have performed more than 50 such autopsies, extending our rapid postmortem banking procedures to all major bodily organs and tissues. Although this expansion has been done in the interest of pursuing research in diseases of other organ systems, it has been increasingly recognized that concurrent disease in other organ systems may contribute to the clinical expression of neurodegenerative disease. Banking tissue from throughout the body has also helped diversify our funding sources, allowing for greater financial stability.

\section{Study of freeze-thaw effects and CSF pH on tissue} RNA integrity

We have long suspected, on the basis of our tissue banking experience, that most of the molecular degradation that occurs in banked tissue is due to repeated freeze-thaw cycles, which occur due to improper handling during dissection for tissue retrieval or due to freezer malfunctions. Our freezers are currently protected by temperature-sensitive alarms that automatically telephone maintenance and tissue banking personnel when the temperature reaches a certain level. More protection is preferable, with $\mathrm{CO} 2$ tanks for backup cooling the optimum (but expensive) approach. We plan to systematically investigate the effects of thawing and refreezing on RNA integrity, by deliberately thawing and freezing small samples of brain tissue over varying time intervals and temperatures.

\section{Biological materials allocation procedure}

Requests for biological materials are granted by a committee of SHRI scientists on the basis of availability and scientific merit. Investigators must first establish appropriate scientific credentials by providing a recent biosketch or curriculum vita. The request is generally granted if it is small or does not seriously deplete a particular resource but receives greater scrutiny if it is for a small, critical area like hippocampus or if it is a large request requiring several days to put together. A base charge of $\$ 2000$ is required to fill a typical small request, in order to partially recover the costs of the neuropathologist's and coordinator's time assisting with study design, case selection, database searches, retrieval and/or dissection, packaging, shipping and continuing 
correspondence. Larger requests are assessed proportionately larger cost recovery fees. Requests from for-profit companies are negotiated on a contract-bycontract basis, with generally larger fees assessed. The general principle applied to all tissue transactions at SHRI is that the user should help defray the expenses of running the program. As academic users generally do not have large budgets, their ability to pay is limited. Rather than deny these users access to the resource, we generally grant their requests even though their payments are less than our costs. As forprofit organizations are often able to reimburse us the full cost of the tissue, negotiations generally aim to obtain this. We have calculated that the cost of following one subject with annual clinical assessments until death, and then performing the autopsy, the neuropathological examination, tissue storage, database upkeep and responding to tissue requests, is at least $\$ 20,000$ per subject, based on the annual operating expenses of the program (clinical and postmortem costs) divided by the number of autopsies per year. The fees charged to users generally never come close to meeting the operating costs. In a typical year, user fees recoup less than $10 \%$ of our costs. Therefore we consider it ethically sound to pursue higher payments from organizations that have greater resources, and these are generally for-profit organizations. In practice, the majority of the program's funding comes from competitive grants, including subcontracts on investigator-initiated research grants and dedicated core grants (SHRI has the Neuropathology Core for the National Institute on Aging's Arizona Alzheimer's Disease Core Center and the Neuropathology Core for the state of Arizona-funded Arizona Parkinson's Disease Center).

\section{Distribution of biological materials to researchers}

Over a recent 4-year-period (01/01/2001-08/16/ 2005), 270 separate distributions, each representing a separate tissue retrieval and shipment of a set of requested samples, were made. Of these, 174 distributions were to 20 separate Arizona ADCC-affiliated researchers while 95 distributions were to 33 different researchers located outside of the Arizona ADCC. Over this same time period, biological materials supplied by the SHRI Brain Donation Program supported more than 49 grants to 26 researchers and a total of 71 publications. Of the 53 researchers supplied, 50 worked for "not-for-profit" organizations while 3 were from "for-profit" organizations.

\section{Protection of neuropathology core workers and tissue users}

Health risks to individuals exposed to human tissue are minimized by the use of a number of precautionary measures. The process begins with screening of medical records at the time of enrollment and repeated screens with each clinical visit and at the time of death. Those individuals with a medical history of a serious infectious pathogen are excluded from enrollment or autopsy. This includes individuals with active or carrier status for hepatitis B, hepatitis C, HIV, syphilis, tuberculosis, Creutzfeldt-Jakob disease (CJD) and acute or chronic active CNS infections of any type. As SHRI is a private research organization, not a diagnostic autopsy service, it is our option to refuse to perform an autopsy. In the 10years since this telephone protocol was developed, only four subjects have been rejected for the presence of a hazardous infectious disease at the time of death, reflecting the low rate of these infectious diseases in our study population. Three of these rejections were for high risk of CJD, and one of the three was later confirmed as CJD by the National Prion Disease Surveillance Laboratory at Case Reserve University in Cleveland. The fourth rejection was for sepsis with methicillin-resistant Staphylococcus aureus.

Staff involved in brain removal and tissue processing are encouraged to have hepatitis A and B vaccination; during procedures involving exposure to fresh or frozen human tissue, staff wear protective clothing including hoods or caps, eye protection, masks, gowns, gloves and boots. Postmortem blood serum from each autopsied patient is sent for diagnostic serology for the detection of hepatitis B and C, syphilis and HIV. If any of these are indicative of the presence of these pathogens, all fresh or frozen tissue is discarded. If potentially infectious contamination of an individual occurs, such as splashing of fresh tissue fluids into the eyes or into a wound, the individual receives appropriate first aid measures at the scene and then is taken to a nearby Emergency Room. All Institute staff receive, upon first hiring, a full day of training in laboratory safety, including biohazard safety precautions. 
Strategy for the future

It is anticipated that continual technological advances will allow ever more refined investigations into the molecular basis of disease. There will thus continue to be a need for brain banks, and the importance of the tissue is likely to increase as the methods become more powerful. Additionally, as the number of subjects with banked tissue and neuropathological diagnoses increases, population-level investigations using epidemiological methods will be possible. Such "autopsyverified epidemiology" has the potential to add precision to the knowledge base that has previously been based on clinical diagnoses, with their inherently higher rate of diagnostic misclassification. At SHRI, our primary field of study will continue to be normal aging and age-related disease. We will strive to increasingly relate molecular-level findings not only to physiology, but also to health care, behavior, sociology and economics. Through this multifaceted approach, we hope to help reduce the negative aspects of aging.

Acknowledgements The Brain Donation Program is supported by the citizens of Sun City, Sun City West and Sun City Grand, the National Institute on Aging (P30 AG19610 Arizona Alzheimer's Disease Core Center), the Arizona Department of Health Services (contract 211002, Arizona Alzheimer's Consortium), the Arizona Biomedical Research Commission (contracts 4001, 0011 and 05-901) and the Prescott Family Initiative of the Michael J. Fox Foundation for Parkinson's Research.

Open Access This article is distributed under the terms of the Creative Commons Attribution Noncommercial License which permits any noncommercial use, distribution, and reproduction in any medium, provided the original author(s) and source are credited.

\section{References}

Adachi T, Inanami O, Sato A (1992) Nitric oxide (NO) is involved in increased cerebral cortical blood flow following stimulation of the nucleus basalis of Meynert in anesthetized rats. Neurosci Lett 139:201-204

Beach TG, Tago H, Nagai T, Kimura H, McGeer PL, McGeer EG (1987) Perfusion-fixation of the human brain for immunohistochemistry: comparison with immersion-fixation. J Neurosci Methods 19:183-192

Beach TG, Sue L, Scott S, Layne K, Newell A, Walker D, Baker M, Sahara N, Yen SH, Hutton M, Caselli R, Adler C, Connor D, Sabbagh M (2003) Hippocampal sclerosis dementia with tauopathy. Brain Pathol 13:263-278

Beach TG, Walker DG, Sue LI, Newell A, Adler CC, Joyce JN (2004) Substantia nigra Marinesco bodies are associated with decreased striatal expression of dopaminergic markers. J Neuropathol Exp Neurol 63:329-337

Braak H, Braak E (1991) Demonstration of amyloid deposits and neurofibrillary changes in whole brain sections. Brain Pathol 1:213-216

Castano EM, Roher AE, Esh CL, Kokjohn TA, Beach T (2006) Comparative proteomics of cerebrospinal fluid in neuropathologically-confirmed Alzheimer's disease and nondemented elderly subjects. Neurol Res 28:155-163

Catts VS, Catts SV, Fernandez HR, Taylor JM, Coulson EJ, Lutze-Mann LH (2005) A microarray study of post-mortem mRNA degradation in mouse brain tissue. Brain Res Mol Brain Res 138:164-177

Cummings TJ, Strum JC, Yoon LW, Szymanski MH, Hulette CM (2001) Recovery and expression of messenger RNA from postmortem human brain tissue. Mod Pathol 14:1157-1161

Dickson DW (2005) Required techniques and useful molecular markers in the neuropathologic diagnosis of neurodegenerative diseases. Acta Neuropathol (Berl) 109(1):14-24

Ellis RJ, Jan K, Kawas C, Koller WC, Lyons KE, Jeste DV, Hansen LA, Thal LJ (1998) Diagnostic validity of the dementia questionnaire for Alzheimer disease. Arch Neurol 55:360-365

Ferrer I, Santpere G, Arzberger T, Bell J, Blanco R, Boluda S, Budka H, Carmona M, Giaccone G, Krebs B, Limido L, Parchi P, Puig B, Strammiello R, Strobel T, Kretzschmar $\mathrm{H}$ (2007) Brain protein preservation largely depends on the postmortem storage temperature: implications for study of proteins in human neurologic diseases and management of brain banks: a BrainNet Europe Study. J Neuropathol Exp Neurol 66:35-46

Gartner U, Janke C, Holzer M, Vanmechelen E, Arendt T (1998) Postmortem changes in the phosphorylation state of tau-protein in the rat brain. Neurobiol Aging 19: 535-543

Gundersen HJ, Bagger P, Bendtsen TF, Evans SM, Korbo L, Marcussen N, Moller A, Nielsen K, Nyengaard JR, Pakkenberg B (1988) The new stereological tools: disector, fractionator, nucleator and point sampled intercepts and their use in pathological research and diagnosis. APMIS 96:857-881

Gustavsson JP, Asberg M, Schalling D (1997) The healthy control subject in psychiatric research: impulsiveness and volunteer bias. Acta Psychiatr Scand 96:325-328

Hardy JA, Wester P, Winblad B, Gezelius C, Bring G, Eriksson A (1985) The patients dying after long terminal phase have acidotic brains; implications for biochemical measurements on autopsy tissue. J Neural Transm 61:253-264

Harrison PJ, Heath PR, Eastwood SL, Burnet PW, McDonald B, Pearson RC (1995) The relative importance of premortem acidosis and postmortem interval for human brain gene expression studies: selective mRNA vulnerability and comparison with their encoded proteins. Neurosci Lett 200:151-154

Hixson JE, Vernier DT (1990) Restriction isotyping of human apolipoprotein $\mathrm{E}$ by gene amplification and cleavage with HhaI. J Lipid Res 31:545-548

Hynd MR, Lewohl JM, Scott HL, Dodd PR (2003) Biochemical and molecular studies using human autopsy brain tissue. J Neurochem 85:543-562 
Johanneson B, Steinsson K, Lindqvist AK, Kristjansdottir H, Grondal G, Sandino S, Tjernstrom F, Sturfelt G, Granados-Arriola J, Alcocer-Varela J, Lundberg I, Jonasson I, Truedsson L, Svenungsson E, Klareskog L, AlarconSegovia D, Gyllensten UB, Alarcon-Riquelme ME (1999) A comparison of genome-scans performed in multicase families with systemic lupus erythematosus from different population groups. J Autoimmun 13:137-141

Johnson SA, Morgan DG, Finch CE (1986) Extensive postmortem stability of RNA from rat and human brain. J Neurosci Res 16:267-280

Johnston NL, Cervenak J, Shore AD, Torrey EF, Yolken RH (1997) Multivariate analysis of RNA levels from postmortem human brains as measured by three different methods of RT-PCR. Stanley Neuropathology Consortium. J Neurosci Methods 77:83-92

Karkela JT (1993) Critical evaluation of postmortem changes in human autopsy cisternal fluid. Enzymes, electrolytes, acid-base balance, glucose and glycolysis, free amino acids and ammonia. Correlation to total brain ischemia. $\mathbf{J}$ Forensic Sci 38:603-616

Kingsbury AE, Foster OJ, Nisbet AP, Cairns N, Bray L, Eve DJ, Lees AJ, Marsden CD (1995) Tissue pH as an indicator of mRNA preservation in human post-mortem brain. Brain Res Mol Brain Res 28:311-318

Kuo YM, Emmerling MR, Bisgaier CL, Essenburg AD, Lampert HC, Drumm D, Roher AE (1998) Elevated lowdensity lipoprotein in Alzheimer's disease correlates with brain abeta 1-42 levels. Biochem Biophys Res Commun 252:711-715

Kuo YM, Emmerling MR, Lampert HC, Hempelman SR, Kokjohn TA, Woods AS, Cotter RJ, Roher AE (1999) High levels of circulating Abeta42 are sequestered by plasma proteins in Alzheimer's disease. Biochem Biophys Res Commun 257:787-791

Kuo YM, Kokjohn TA, Kalback W, Luehrs D, Galasko DR, Chevallier N, Koo EH, Emmerling MR, Roher AE (2000a) Amyloid-beta peptides interact with plasma proteins and erythrocytes: implications for their quantitation in plasma. Biochem Biophys Res Commun 268:750-756

Kuo YM, Kokjohn TA, Watson MD, Woods AS, Cotter RJ, Sue LI, Kalback WM, Emmerling MR, Beach TG, Roher $\mathrm{AE}$ (2000b) Elevated abeta42 in skeletal muscle of Alzheimer disease patients suggests peripheral alterations of AbetaPP metabolism. Am J Pathol 156:797-805

Leong AS, Gilham PN (1989) The effects of progressive formaldehyde fixation on the preservation of tissue antigens. Pathology 21:266-268

Li JZ, Vawter MP, Walsh DM, Tomita H, Evans SJ, Choudary PV, Lopez JF, Avelar A, Shokoohi V, Chung T, Mesarwi O, Jones EG, Watson SJ, Akil H, Bunney WE Jr, Myers RM (2004) Systematic changes in gene expression in postmortem human brains associated with tissue $\mathrm{pH}$ and terminal medical conditions. Hum Mol Genet 13:609-616

Lim A, Kukull W, Nochlin D, Leverenz J, McCormick W, Bowen J, Thompson J, Peskind ER, Raskind M (1999) Clinico-neuropathological correlation of Alzheimer's disease in a community-based case series. J Am Geriatr Soc 47:564-569
Lio D, Pes GM, Carru C, Listi F, Ferlazzo V, Candore G, Colonna-Romano G, Ferrucci L, Deiana L, Baggio G, Franceschi C, Caruso C (2003) Association between the HLA-DR alleles and longevity: a study in Sardinian population. Exp Gerontol 38:313-317

Ludes B, Pfitzinger H, Mangin P (1993) DNA fingerprinting from tissues after variable postmortem periods. J Forensic Sci 38:686-690

Lue LF, Walker DG (2002) Modeling Alzheimer's disease immune therapy mechanisms: interactions of human postmortem microglia with antibody-opsonized amyloid beta peptide. J Neurosci Res 70:599-610

Lue LF, Brachova L, Walker DG, Rogers J (1996) Characterization of glial cultures from rapid autopsies of Alzheimer's and control patients. Neurobiol Aging 17:421-429

Mandel FS, Weiner M, Kaplan S, Pelcovitz D, Labruna V (2000) An examination of bias in volunteer subject selection: findings from an in-depth child abuse study. J Trauma Stress 13:77-88

Mathews CA, Reus VI, Bejarano J, Escamilla MA, Fournier E, Herrera LD, Lowe TL, McInnes LA, Molina J, Ophoff RA, Raventos H, Sandkuijl LA, Service SK, Spesny M, Leon PE, Freimer NB (2004) Genetic studies of neuropsychiatric disorders in Costa Rica: a model for the use of isolated populations. Psychiatr Genet 14:13-23

McGeer PL, McGeer EG (1976) Enzymes associated with the metabolism of catecholamines, acetylcholine and gaba in human controls and patients with Parkinson's disease and Huntington's chorea. J Neurochem 26:65-76

Morrison-Bogorad M, Zimmerman AL, Pardue S (1995) Heatshock 70 messenger RNA levels in human brain: correlation with agonal fever. J Neurochem 64:235-246

Palmer AM, Lowe SL, Francis PT, Bowen DM (1988) Are post-mortem biochemical studies of human brain worthwhile? Biochem Soc Trans 16:472-475

Pardue S, Zimmerman AL, Morrison-Bogorad M (1994) Selective postmortem degradation of inducible heat shock protein 70 (hsp70) mRNAs in rat brain. Cell Mol Neurobiol 14:341-357

Perry EK, Perry RH, Tomlinson BE (1982) The influence of agonal status on some neurochemical activities of postmortem human brain tissue. Neurosci Lett 29:303-307

Peschken CA, Esdaile JM (1999) Rheumatic diseases in North America's indigenous peoples. Semin Arthritis Rheum 28:368-391

Pollard K, Lunny D, Holgate CS, Jackson P, Bird CC (1987) Fixation, processing, and immunochemical reagent effects on preservation of T-lymphocyte surface membrane antigens in paraffin-embedded tissue. $\mathrm{J}$ Histochem Cytochem 35:1329-1338

Preece P, Cairns NJ (2003) Quantifying mRNA in postmortem human brain: influence of gender, age at death, postmortem interval, brain $\mathrm{pH}$, agonal state and interlobe mRNA variance. Brain Res Mol Brain Res 118: 60-71

Ravid R, Van Zwieten EJ, Swaab DF (1992) Brain banking and the human hypothalamus-factors to match for, pitfalls and potentials. Prog Brain Res 93:83-95

Rogers J, Lue LF, Walker DG, Yan SD, Stern D, Strohmeyer R, Kovelowski CJ (2002) Elucidating molecular 
mechanisms of Alzheimer's disease in microglial cultures. Ernst Schering Res Found Workshop, pp 25-44

Rogers J, Li R, Mastroeni D, Grover A, Leonard B, Ahern G, Cao P, Kolody H, Vedders L, Kolb WP, Sabbagh M (2006) Peripheral clearance of amyloid beta peptide by complement C3-dependent adherence to erythrocytes. Neurobiol Aging 27:1733-1739

Roher AE, Kuo YM, Esh C, Knebel C, Weiss N, Kalback W, Luehrs DC, Childress JL, Beach TG, Weller RO, Kokjohn TA (2003) Cortical and leptomeningeal cerebrovascular amyloid and white matter pathology in Alzheimer's disease. Mol Med 9:112-122

Sofuoglu M, Dudish-Poulsen S, Nicodemus KK, Babb DA, Hatsukami DK (2000) Characteristics of research volunteers for inpatient cocaine studies: focus on selection bias. Addict Behav 25:785-790

Spokes EG (1979) An analysis of factors influencing measurements of dopamine, noradrenaline, glutamate decarboxylase and choline acetylase in human post-mortem brain tissue. Brain 102:333-346

Spokes EG, Koch DJ (1978) Post-mortem stability of dopamine, glutamate decarboxylase and choline acetyltransferase in the mouse brain under conditions simulating the handling of human autopsy material. J Neurochem 31:381-383

Stan AD, Ghose S, Gao XM, Roberts RC, Lewis-Amezcua K, Hatanpaa KJ, Tamminga CA (2006) Human postmortem tissue: what quality markers matter? Brain Res 1123:1-11
Tomita H, Vawter MP, Walsh DM, Evans SJ, Choudary PV, Li J, Overman KM, Atz ME, Myers RM, Jones EG, Watson SJ, Akil H, Bunney WE Jr (2004) Effect of agonal and postmortem factors on gene expression profile: quality control in microarray analyses of postmortem human brain. Biol Psychiatry 55:346-352

Vanderburg CR, Pfanni R, Tian D, Kiehl T-R, Hsi T, HedleyWhyte ET, Frosch MP (2005) Factors influencing postmortem RNA integrity in human brain. J Neuropathol Exp Neurol 64:443-443

Vonsattel JP, Aizawa H, Ge P, DiFiglia M, McKee AC, MacDonald M, Gusella JF, Landwehrmeyer GB, Bird ED, Richardson EP Jr (1995) An improved approach to prepare human brains for research. J Neuropathol Exp Neurol 54:42-56

Walker DG, Lue LF (2005) Investigations with cultured human microglia on pathogenic mechanisms of Alzheimer's disease and other neurodegenerative diseases. J Neurosci Res 81:412-425

West MJ (1999) Stereological methods for estimating the total number of neurons and synapses: issues of precision and bias. Trends Neurosci 22:51-61

Yates CM, Butterworth J, Tennant MC, Gordon A (1990) Enzyme activities in relation to $\mathrm{pH}$ and lactate in postmortem brain in Alzheimer-type and other dementias. J Neurochem 55:1624-1630 